\title{
Preparation of a Highly Active Cu/Zno-Based Catalysts for the Methanol Synthesis with the Photochemical Method
}

\author{
Maja Pori $^{1}$, Blaž Likozar ${ }^{2}$, Marjan Marinšek ${ }^{3}$, Zorica Crnjak Orel ${ }^{4}$ \\ $1,2,4$ National Institute of Chemistry \\ Hajdrihova 19, Ljubljana, Slovenia \\ Maja.Pori@ki.si; Blaz.Likozar@ki.si; Zorica.Crnjak.Orel@ki.si \\ ${ }^{3}$ Faculty of chemistry and chemical technology, Department of Chemical Engineering and Technical Safety, \\ 113 Večna pot, Ljubljana, Slovenia \\ Marjan.Marinsek@fkkt.uni-lj.si
}

Commercially, methanol is produced from syngas over ternary $\mathrm{Cu} / \mathrm{ZnO} / \mathrm{Al}_{2} \mathrm{O}_{3}$ catalysts. In this study we report on preparation, structural properties and activity of a novel $\mathrm{Cu} / \mathrm{ZnO}$-based analogues, prepared with the photochemical method. Different from the conventional ones, where the oxides are mixed, $\mathrm{CuO}$ were chemically anchored on the surface of the synthesized $\mathrm{ZnO}$ support in the synthesized catalysts. The concentration of the deposited $\mathrm{CuO}$ was controlled by reaction time $(1,4,12 \mathrm{~h})$ and concentration of the copper nitrate solution $(0.5,0.75,1 \mathrm{mM})$ in order to obtain a wide range of $\mathrm{CuO}$ crystal size. The morphology and crystal structure of the $\mathrm{CuO} / \mathrm{ZnO}$ composites was examined by means of scanning microscopy (SEM), X-ray diffraction (XRD) and Fourier transform infrared (FTIR). The composites were reduced in $\mathrm{H}_{2} / \mathrm{Ar}$ flow and were subsequently tested for methanol synthesis activity in a model reaction system at mild reaction conditions (1bar, $250{ }^{\circ} \mathrm{C}$ ), using $\mathrm{H}_{2}$. and $\mathrm{CO}_{2}$ mixture as a feed. The activity of the prepared catalysts was compared to the activity of the commercial ones and was found out to be up to 18 -fold higher in comparison to the conventional analogues. The superior activity is suggested to arise from improved catalysts morphology, allowing the reaction molecules easier to bind to the catalysts surface. The results showed that the size of $\mathrm{Cu}$ crystallites influenced the formation of methanol, which is favoured over catalysts with smaller $\mathrm{Cu}$ crystal sizes $(43-46 \mathrm{~nm})$ when compared to those with greater ones $(55-62 \mathrm{~nm})$. The latter is proposed to arise from the high dispersion of $\mathrm{Cu}$ crystallites on the $\mathrm{ZnO}$ surface and consequently from a larger interfacial contact between $\mathrm{Cu}$ and $\mathrm{ZnO}$. The activities for $\mathrm{H}_{2} \mathrm{O}$ and $\mathrm{CO}$ formation of the prepared catalysts were significantly lower in comparison to the conventional ones, explaining the long term high stability of the prepared catalysts during methanol synthesis. 